Main Outcome Measures: Mean weekly duration of self-reported tobacco smoke exposure; geometric mean salivary cotinine. Cotinine is an excellent marker of exposure to tobacco. Low levels indicate exposure to other people's smoke; $12 \mathrm{ng} / \mathrm{ml}$ is the best cutoff for personal tobacco use. Analyses adjusted for the complex (stratified, clustered) sampling design and weighted for nonresponse to interview and saliva sample, as appropriate.

Results: Most adult non-smokers reported no-one smoked in the home most days (93\% before and $95 \%$ after 1 st July 2007). Nonsmokers' mean self-reported exposure to tobacco smoke fell from $4.2 \mathrm{hrs}(95 \%$ CI 3.6 to 4.9$)$ before to $2.0 \mathrm{hrs}$ (1.5 to 2.4 ) after 1 st July in men and from $3.5 \mathrm{hrs}$ (2.9 to 4.1$)$ to $1.4 \mathrm{hrs}(1.0$ to 1.7$)$ in women (both $\mathrm{p}<0.001$ ). Exposure was inversely related to age-group but fell most in those with the highest exposure: from 5.9 hrs (4.9 to 6.9) to $2.8 \mathrm{hrs}(2.3$ to $3.3, \mathrm{p}<0.001)$ aged $16-34 \mathrm{yrs}$; from $3.4 \mathrm{hrs}(2.9$ to $4.0)$ to 1.4 hrs (1.0 to 1.7, p<0.001) aged 35-64 yrs; and 2.1 hrs (1.5 to 2.7$)$ to $0.9 \mathrm{hrs}(0.4$ to $1.4, p=0.002)$ aged $65+$. Similar falls occurred in all three NS-SEC groups: professional/managerial from $4.2 \mathrm{hrs}$ ( 3.5 to 5.0 ) to $1.7 \mathrm{hrs}$ (1.3 to 2.1 ); intermediate from $3.9 \mathrm{hrs}$ (2.9 to 4.8 ) to 1.7 hrs (1.4 to 2.1); and routine/manual from 7.9 hrs (6.7 to 9.1 ) to $4.9 \mathrm{hrs}$ (4.0 to 5.8 ) (all $\mathrm{p}<0.001)$. Overall, the proportion with undetectable salivary cotinine levels rose from $32 \%$ to $46 \%$ of cotinine-validated non-smokers. Geometric mean cotinine levels in cotinine-validated non-smoking adults fell from $0.20 \mathrm{ng} / \mathrm{ml}(95 \%$ CI 0.18 to 0.22$)$ in the first half of 2007 to $0.14 \mathrm{ng} /$ $\mathrm{ml}(0.13$ to 0.15$)$ after 1 st July 2007 in men and from $0.19 \mathrm{ng} / \mathrm{ml}$ ( 0.17 to 0.21$)$ to $0.12 \mathrm{ng} / \mathrm{ml}(0.11$ to 0.13$)$ respectively in women (both $\mathrm{p}<0.001$ ). As with self-reported exposure, levels before July 2007 were highest in the youngest age-group, who experienced the largest falls: from $0.23 \mathrm{ng} / \mathrm{ml}$ to $0.15 \mathrm{ng} / \mathrm{ml}$ aged $16-34, \mathrm{p}<0.001$; $0.17 \mathrm{ng} / \mathrm{ml}$ to $0.11 \mathrm{ng} / \mathrm{ml}$ aged $35-64, \mathrm{p}<0.001$; and $0.17 \mathrm{ng} / \mathrm{ml}$ to $0.14 \mathrm{ng} / \mathrm{ml}$ aged $65+, \mathrm{p}=0.001$. Similar, significant falls occurred in all three NS-SEC groups.

Conclusion: The legislation has been successful in its primary aim, to reduce the exposure of non-smokers to tobacco smoke pollution. It has decreased absolute inequalities.

\section{THE BENEFITS OF STOPPING SMOKING}

${ }^{1} \mathrm{~K}$ Pirie, ${ }^{2} \mathrm{R}$ Peto, ${ }^{1} \mathrm{G}$ Reeves, 'V Beral, on behalf of the Million Women Study Collaborators ${ }^{1}$ Cancer Epidemiology Unit, University of Oxford, Oxford, UK; ${ }^{2}$ Clinical Trial Service Unit, University of Oxford, Oxford, UK

\section{doi:10.1136/jech.2009.096719y}

Background: Although much is known about the effects of smoking, there is limited reliable information on the effects of stopping smoking on mortality.

Objectives: To investigate the association between stopping smoking and the risk of all-cause mortality and of cause specific mortality, including deaths due to cancer and vascular disease. In particular, to investigate how the risks for former smokers compare with those of lifelong non-smokers as the period of time since quitting smoking increases.

Design: Prospective cohort study.

Participants and Setting: 1.3 million UK women were recruited in 1996-2001, and were resurveyed around 3 years later with a $65 \%$ response rate. Women were included in these analyses $(n=700000)$ if they had completed both study questionnaires, and if smoking status was classified in the same way (current, former, never smoker) on both. Participants were followed prospectively for incident cancers and death through NHS cancer registration and death records.

Main Outcome Measures: Relative risks of all-cause and causespecific mortality for former smokers compared with lifelong nonsmokers, adjusting for age, region, socioeconomic status and body mass index.
Results: Women were followed up for a mean duration of 6.7 years, during which time 21469 deaths occurred, including 12588 deaths due to cancer and 4314 due to vascular disease. Current smokers were almost three times more likely to die from any cause than lifelong non-smokers (RR 2.8, 95\% CI 2.7 to 2.9). The risk for former smokers declined with every decade that passed since stopping smoking, with women who had stopped 30 or more years ago at no greater risk of mortality than lifelong non-smokers (RR $1.0,95 \%$ CI 0.9 to 1.1 ). Results will be presented according to time since stopping smoking, and by cause of mortality.

Conclusions: The Million Women Study is the largest study to date to examine the direct health effects of smoking, and the benefits of stopping, in women who have smoked throughout much of their adult lives. Much of the excess mortality risk associated with smoking is removed by stopping smoking, with former smokers who had not smoked for 30 years or more at no greater risk than women who had never smoked.

\section{WEIGHT CHANGE OVER EIGHT YEARS IN RELATION TO BASELINE BODY MASS INDEX IN A COHORT OF CONTINUING AND QUITTING SMOKERS}

${ }^{1} \mathrm{D}$ Lycett, ${ }^{1 P}$ Aveyard, ${ }^{2} \mathrm{M}$ Munafo, ${ }^{3} \mathrm{E}$ Johnstone, ${ }^{4} \mathrm{M}$ Murphy. ${ }^{1} U K$ Centre for Tobacco Control Studies, Primary Care Clinical Sciences, University of Birmingham, Birmingham, UK; ${ }^{2}$ Department of Experimental Psychology, University of Bristol, Bristol, UK: ${ }^{3}$ Department of Clinical Pharmacology, University of Oxford, Oxford, UK: ${ }^{4}$ Childhood Cancer Research Group, University of Oxford, Oxford, UK

doi:10.1136/jech.2009.096719z

Objective: To examine the effect of body mass index (BMI) on weight change over 8 years in a cohort of continuing smokers and a cohort that quit and remained abstinent.

Design: 8 year prospective cohort study.

Data Source: Participants smoking $>15$ cigarettes daily enrolled in a clinical trial of nicotine patch or placebo in Oxfordshire general practices and were reviewed 8 years later.

Population: 832 male and female participants. Abstainers were 85 participants who were biochemically proven abstinent at 3,6 , 12 months and 8 years. 613 people were smoking at each follow-up, 26 relapsed and 116 quit after 1 year.

Statistical Methods: Means, SDs, and 95\% CIs were calculated for change in weight by smoking status. Linear regression analysis, using baseline BMI as an effect modifier, was used to investigate whether the effect of smoking status on weight change was dependent on baseline BMI in smokers and continuous abstainers. Modelling proceeded with separate regression equations for smokers and abstainers. Confounding variables were adjusted for.

Results: Abstainers gained $8.79 \mathrm{~kg}$ (SD 6.36, 95\% CI 7.42 to 10.17). Smokers gained $2.24 \mathrm{~kg}(6.65,95 \%$ CI 1.7 to 2.77$)$. Relapsers gained $3.28 \mathrm{~kg}(7.16,95 \%$ CI 0.328 to 6.24). Later abstainers gained $8.33 \mathrm{~kg}$ (8.04, 95\% CI 6.85 to 9.81). The difference in weight gain $(6.56 \mathrm{~kg}$, $95 \%$ CI 5.05 to $8.06, p<0.001$ ) between abstainers and smokers was modified by baseline BMI. In abstainers a positive quadratic relationship of BMI fit best, resulting in a J-shaped curve. In persistent smokers there was a negative linear relationship of BMI $(p<0.001)$. The model predicted that abstainers with a baseline BMI of 18 would gain $6 \mathrm{~kg}$, with a BMI of 23 gain $5 \mathrm{~kg}$, and with a BMI of 33 gain $14 \mathrm{~kg}$ more than would have been the case had they continued smoking for eight years.

Conclusions: Obese smokers who continue smoking are likely to not change or lose weight over eight years while obese people who quit are likely to gain the most weight. Weight gain is not as harmful as continuing smoking, but weight gain prevention interventions for obese people trying to stop smoking are needed. 